\title{
Steel Fibre Reinforcing Characteristics on the Size Reduction of Fly Ash Based Concrete
}

\author{
Sounthararajan Vallarasu Manoharan and Sivakumar Anandan \\ Structural Engineering Division, School of Mechanical and Building Sciences, VIT University, Vellore, Tamil Nadu 632014, India \\ Correspondence should be addressed to Sivakumar Anandan; siva_iitm@rediffmail.com
}

Received 31 May 2014; Revised 1 October 2014; Accepted 9 October 2014; Published 4 November 2014

Academic Editor: Cumaraswamy Vipulanandan

Copyright ( 2014 S. Vallarasu Manoharan and S. Anandan. This is an open access article distributed under the Creative Commons Attribution License, which permits unrestricted use, distribution, and reproduction in any medium, provided the original work is properly cited.

\begin{abstract}
The behavior of glued steel fibres in high strength concrete with size reduction properties of concrete has been attempted. Glued steel fibres with both ends hooked having length to diameter ratio of 70 was added at a dosage level of $0.5 \%$ to $1.5 \%$ by volume fraction. The study was carried out to analyze the effects of fibre addition on the thickness reduction of concrete element. A high strength concrete mixture was designed and various thicknesses of concrete prisms were casted for different volume fraction of steel fibres. The hardened concrete properties were determined based on the mix constituents such as water to binder ratio 0.3 (w/b), superplasticizer dosage, fine to coarse aggregate ratio $0.6(\mathrm{~F} / \mathrm{c})$, and fly ash replacement level at $25 \%$ and $50 \%$ by weight of binder content. The experimental test results showed that the flexural strength varies with respect to the depth of concrete specimen. It can be observed that the reduction in size up to $10 \%$ size containing $25 \%$ fly ash with $1.5 \%$ steel fibres showed better strength enhancement of 4.70 MPa and 6.69 MPa for 7 days and 28 days, respectively. Also, the addition of steel fibres at higher percentage of fly ash containing 50\% showed better improvement in the flexural strength for the size reduction at 5\%, when compared to plain concrete beam which exhibited higher stress carrying capacity of $6.08 \mathrm{MPa}$ at 28 days and showed an increase of $7.99 \%$.
\end{abstract}

\section{Introduction}

Fibre addition in plain concrete are known to improve the brittle failure properties of concrete as it controls the crack propagation in the matrix. However, the careful selection of the type of fibres can be potentially used to improve the toughness of concrete. The dispersion of fibres randomly in the concrete can promulgate the homogeneous properties in all directions. The major role of fibres being incorporated in plain concrete is to develop adequate tensile strength for effective crack bridging upon loading. It can be observed that the addition of fibres in concrete shows higher degree of ductile failure leading to high crack width reduction. The plastic deformation occurring in the postcrack region is an added advantage which is primarily borne by the discrete reinforcing mechanisms. The typical application of fibres is noted in the case of high strength concrete due to high brittleness fibres having more significant benefits in terms of improving flexural strength, elastic modulus, and long term durability. High strength concrete exhibits more brittleness under compression and addition of steel fibres in concrete improves the confinement, durability, and deformability of the concrete $[1,2]$. In several research studies it was observed that the addition of steel fibers in conventional concrete greatly improved the flexural strength, fracture toughness, thermal shock resistance, and impact loading for various grades of concrete $[3,4]$. It was also demonstrated that the addition of steel fibres showed significant improvement on shear capacity of concrete or it can partially replace the vertical stirrups in RC structural members. The application implies addition of steel fibres in critical sections such as beam-column junctions gives adequate ductility. The steel fibres can improve the postcrack performance and reduce the brittle behavior of normal concrete and high-strength concrete, improving the failure properties of high strength concrete $[5,6]$. It was also observed that propagation of the crack is controlled by the steel fibres along the fracture plane. Fibres usually bonded with matrix exhibit crack propagation after matrix cracking and showed pullout of the fibres from the matrix exhibiting the bond strength between steel fibre 
TABle 1: Properties of cement used (OPC-53 grade).

\begin{tabular}{lccccccc}
\hline Description & $\begin{array}{c}\text { Consistency } \\
(\%)\end{array}$ & $\begin{array}{c}\text { Initial setting } \\
\text { time }\end{array}$ & $\begin{array}{c}\text { Final setting } \\
\text { time }\end{array}$ & $\begin{array}{c}\text { Specific } \\
\text { gravity }\end{array}$ & $\begin{array}{c}\text { Fineness of } \\
\text { cement }(\%)\end{array}$ & \multicolumn{2}{c}{$\begin{array}{c}\text { Compressive strength of } \\
\text { cement mortar }(1: 3) \\
(\mathrm{MPa})\end{array}$} \\
\hline Values & 31 & \multicolumn{2}{c}{ Minutes } & & & 3 days & 28 days \\
\hline
\end{tabular}

TABLE 2: Properties of glued steel fibres.

\begin{tabular}{lccccccc}
\hline Material & Appearance & $\begin{array}{c}\text { Relative density } \\
(\mathrm{g} / \mathrm{cc})\end{array}$ & Length $(\mathrm{mm})$ & $l / d$ ratio & Diameter $(\mathrm{mm})$ & $\begin{array}{c}\text { Tensile } \\
\text { strength }\end{array}$ & $\begin{array}{c}\text { Failure strain } \\
(\%)\end{array}$ \\
\hline Steel fibres & Both ends hooked & 7.65 & 35 & 70 & 0.5 & $1721 \mathrm{MPa}$ & 3.2 \\
\hline
\end{tabular}

and matrix. Both matrix and fibre tensile strength play an important role on the bond strength or pullout resistance of steel fibre from the matrix [7-9]. It is also concluded that the steel fibre volume fraction and steel fibre tensile strength have no significant effect on compressive strength and modulus of elasticity of concrete. However, the use of high tensile strength steel fibres showed considerable improvement on the split tensile and flexural strength with considerable improvements noted at increased fibre dosage $[10,11]$. It is also emphasized that the bond between the steel fibres and matrix plays an important role in improving ductility, first crack strength, and flexural strength $[12,13]$. From the literature analysis it can be summarized that the fibre reinforcing efficiency depends on the fibre volume fraction and the matrix properties. It can be also noted from the review that compatibility between the matrix and the steel fibre can be very important for improving postcracking behavior and fracture properties of high-strength concrete. It becomes very important to provide a comprehensive understanding of the steel fibre characteristics in concrete with special focus on the reinforcing efficiency in the matrix.

Research Significance. Reinforcing properties of discrete steel fibres in a high strength matrix can provide potential benefits on the postcrack properties as well as strengthening the matrix without cracking. In the present study, a new research finding on the flexural strength improvements with a corresponding reduction in size of concrete element was investigated. This study provides the significance on the overall reduction in concrete volume with the reinforcing efficiency of steel fibres at different volume fraction.

\section{Experimental Methodology}

\subsection{Materials Used}

2.1.1. Ordinary Portland Cement (53 Grade) IS 122621969 [14]. Chemical composition and the basic properties of cement used in the study are given in Table 1 .

2.1.2. Fine Aggregate. The fine aggregate used were obtained from a locally available river bed. The fineness modulus of fine aggregate was observed to be 3.05 with a specific gravity

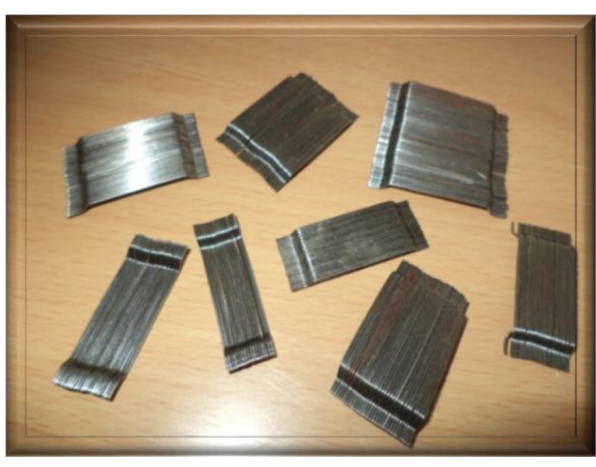

FIGURE 1: Snapshot of glued steel fibres.

of 2.59, and conforms to IS 383-1970 which falls under Zone III gradation.

2.1.3. Coarse Aggregate. Crushed granite blue metal stone used as coarse aggregates used for material is passing through $20 \mathrm{~mm}$ sieve and obtained on $12.5 \mathrm{~mm}$. The fineness modulus of coarse aggregate was observed to be 6.82 and specific gravity 2.61 .

2.1.4. Glued Steel Fibres. Both end hooked glued steel fibres were used in the study. The properties and the snapshot of steel fibres are given in Table 2 and Figure 1.

2.1.5. Chemical Superplasticizer. A commercially available calcium nitrate based accelerator (Cerachem-Acl) was used to accelerate the pozzolanic reaction in fly ash concrete, which had a specific gravity value of 1.82 and solid content of $25 \%$ and also, to improve the workability properties of fresh concrete, polycarboxylate ether based superplasticizer (PCE) was added at $1.5 \%$ (by weight of binder) to obtain the desired workability range of 75 to $100 \mathrm{~mm}$ slump.

2.1.6. Water. Normal potable water is used throughout the experimental works and was free from oils, alkalies, and any other organic impurities.

2.1.7. Mixture Proportions of Test Samples. The experimental investigations so far employed seven concrete mixes ( $\mathrm{MC1}$, 


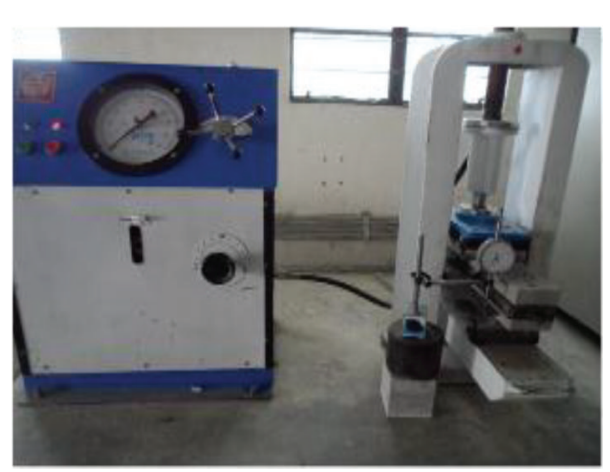

(a)

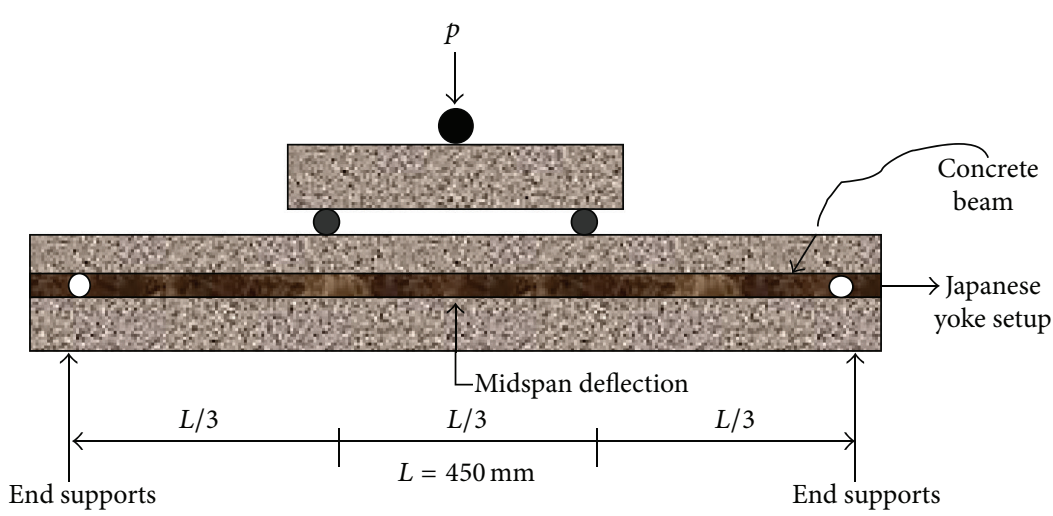

(b)

Figure 2: (a) Experimental test setup for flexural studies. (b) Line sketch of third point loading arrangement of flexural test setup.

TABLE 3: Mix constituents for various proportions of concrete.

\begin{tabular}{lcccccccccc}
\hline Mix Id & w/b ratio & F/c ratio & B/Ta ratio & Fibres $\%$ & Acl \% & Cement & Fly ash & $\begin{array}{c}\text { Fine aggregate } \\
\mathrm{kg} / \mathrm{m}^{3}\end{array}$ & Coarse aggregate & Water \\
\hline MC1 & 0.3 & 0.6 & 0.26 & 0 & 0 & 473 & 0 & 672 & 1113 & 142 \\
MSF1 & 0.3 & 0.6 & 0.26 & 0.5 & 1 & 355 & 118 & 672 & 1113 \\
MSF2 & 0.3 & 0.6 & 0.26 & 1.0 & 1 & 355 & 118 & 672 & 1113 \\
MSF3 & 0.3 & 0.6 & 0.26 & 1.5 & 1 & 237 & 118 & 672 & 142 \\
MSF7 & 0.3 & 0.6 & 0.26 & 0.5 & 1 & 237 & 236 & 672 & 113 \\
MSF8 & 0.3 & 0.6 & 0.26 & 1.0 & 1 & 237 & 236 & 672 & 1113 \\
MSF9 & 0.3 & 0.6 & 0.26 & 1.5 & 1 & 237 & 236 & 672 & 1113 \\
\hline
\end{tabular}

Note: PCE dosage was fixed at $1.5 \%$ by weight of binder content for various mixture proportions.

MSF1, MSF2, MSF3, MSF7, MSF8, and MSF9) with fixed water to binder ratio $(\mathrm{w} / \mathrm{b})$ of 0.3 and fine to coarse aggregate ratio $(\mathrm{F} / \mathrm{c})$ of 0.6 . Also, the replacement level of Class $\mathrm{F}$ fly ash at $25 \%$ and $50 \%$ (by weight of binder content) with glued steel fibres (both end hooked) at $0.5 \%, 1.0 \%$, and $1.5 \%$ (by weight of binder content) was used. In order to improve the rate of strength gain, the addition of accelerator dosage level was fixed at $1 \%$ and $1.5 \%$ of polycarboxylic ether based superplasticizer (PCE) was used for improving the workability. The detailed mixture proportions of various concrete mixes tested in the study are given in Table 3.

2.1.8. Specimen Details. Flexural performance of glued steel fibre based fly ash concretes was assessed by testing flexural strength, absolute toughness, postcrack toughness, and residual strength. Concrete specimens were casted for different sizes and the details are presented in Table 4. The flexural experimental test setup consisting of yoke arrangement is shown in Figure 2(a) and the line sketch of third point loading arrangement is shown in Figure 2(b). This facilitates the prevention of extraneous deflection at the ends. A three-point loading arrangement was used for conducting bending test on the specimen and the central deflection was measured using a mechanical dial gauge of $0.01 \mathrm{~mm}$ accuracy. The specimens were tested as per codal provision (IS) 516-1959 and the postcrack deflection was also measured accurately without any sudden drop in load after peak load. Since the yoke arrangement provides adequate restraint to the specimen at the ends without allowing sudden failure.

This provides an accurate recording of strain during gradual failure of beam due to crack bridging of fibres. This evidently denotes the role of fibres in the postcracking region during flexural bending of the specimen. Based on the loaddeflection plots drawn for the various fibre concretes, the following toughness calculations were made.

(i) Absolute toughness was calculated from the area under entire load-deflection curve from the start of loading till the complete failure of specimen.

(ii) Postpeak toughness was measured from the area between the ultimate load and failure load under load-deflection curve.

(iii) The toughness index is defined as the ratio of average load carrying capacity offered after cracking (due to the presence of steel fibre reinforcement) divided by the flexural tensile strength of the uncracked concrete specimen.

2.1.9. Specimen Preparation and Curing Methods. The concrete constituents were mixed in an electrically operated drum type concrete mixer of $40 \mathrm{Kg}$ capacity. The ingredients were dry mixed initially and then the required mix water is added along with the superplasticizer as well as accelerator. The fresh concrete with molds was compacted by table 
TABLE 4: Specimen details for various mixture proportions of concrete.

\begin{tabular}{lcc}
\hline Shape & Size of the concrete specimens & Tested \\
\hline \multirow{2}{*}{ Prism molds size details } & $100 \times \mathbf{1 0 0} \times 500 \mathrm{~mm}$ (actual size) & \\
& $100 \times \mathbf{9 5} \times 500 \mathrm{~mm}$ (size reduction) & Flexural strength for third point loading \\
& $100 \times \mathbf{9 0} \times 500 \mathrm{~mm}$ (size reduction) & \\
\hline
\end{tabular}

TABLE 5: Flexural strength for various mixture proportions of concrete.

\begin{tabular}{|c|c|c|c|c|c|c|c|c|c|c|c|}
\hline Mix Id & $\mathrm{w} / \mathrm{b}$ ratio & $\mathrm{F} / \mathrm{c}$ ratio & Fly ash (\%) & GSF (\%) & $\operatorname{Acl}(\%)$ & PCE (\%) & $\begin{array}{l}\text { Depth of } \\
\text { prism } \\
(\mathrm{mm})\end{array}$ & $\begin{array}{c}\text { Flexural } \\
\text { strength at } \\
7 \text { days } \\
(\mathrm{MPa})\end{array}$ & $\begin{array}{c}\% \text { of } \\
\text { strength } \\
\text { gain at } 7 \\
\text { days }\end{array}$ & $\begin{array}{c}\text { Flexural } \\
\text { strength at } \\
28 \text { days } \\
(\mathrm{MPa})\end{array}$ & $\begin{array}{c}\% \text { of } \\
\text { strength } \\
\text { gain at } 28 \\
\text { days }\end{array}$ \\
\hline $\mathrm{MCl}$ & 0.3 & 0.6 & 0 & 0 & 0 & 1.5 & 100 & 4.28 & - & 5.63 & - \\
\hline \multirow{4}{*}{ MSF1 } & \multirow{4}{*}{0.3} & \multirow{4}{*}{0.6} & \multirow{4}{*}{25} & \multirow{4}{*}{0.5} & \multirow{4}{*}{1} & \multirow{4}{*}{1.5} & 100 & 4.32 & 0.98 & 5.89 & 4.60 \\
\hline & & & & & & & 95 & 4.10 & -4.21 & 5.57 & -1.07 \\
\hline & & & & & & & 90 & 3.85 & -10.05 & 5.30 & -5.86 \\
\hline & & & & & & & 85 & 3.50 & -18.22 & 4.85 & -13.85 \\
\hline \multirow{4}{*}{ MSF2 } & \multirow{4}{*}{0.3} & \multirow{4}{*}{0.6} & \multirow{4}{*}{25} & \multirow{4}{*}{1.0} & \multirow{4}{*}{1} & \multirow{4}{*}{1.5} & 100 & 4.36 & 1.89 & 5.89 & 6.07 \\
\hline & & & & & & & 95 & 4.25 & -0.70 & 5.74 & 1.95 \\
\hline & & & & & & & 90 & 4.25 & -0.70 & 5.65 & 0.36 \\
\hline & & & & & & & 85 & 3.75 & -12.38 & 5.30 & -5.86 \\
\hline \multirow{4}{*}{ MSF3 } & \multirow{4}{*}{0.3} & \multirow{4}{*}{0.6} & \multirow{4}{*}{25} & \multirow{4}{*}{1.5} & \multirow{4}{*}{1} & \multirow{4}{*}{1.5} & 100 & 4.65 & 8.64 & 6.70 & 25.00 \\
\hline & & & & & & & 95 & 4.50 & 5.14 & 6.45 & 14.56 \\
\hline & & & & & & & 90 & 4.70 & 9.81 & 6.69 & 18.83 \\
\hline & & & & & & & 85 & 4.30 & 0.47 & 5.95 & -3.20 \\
\hline \multirow{4}{*}{ MSF7 } & \multirow{4}{*}{0.3} & \multirow{4}{*}{0.6} & \multirow{4}{*}{50} & \multirow{4}{*}{0.5} & \multirow{4}{*}{1} & \multirow{4}{*}{1.5} & 100 & 3.83 & -10.51 & 5.14 & -8.70 \\
\hline & & & & & & & 95 & 3.75 & -12.38 & 5.05 & -10.30 \\
\hline & & & & & & & 90 & 3.56 & -16.82 & 4.02 & -28.60 \\
\hline & & & & & & & 85 & 3.20 & -25.23 & 3.65 & -35.17 \\
\hline \multirow{4}{*}{ MSF8 } & \multirow{4}{*}{0.3} & & & & & & 100 & 3.43 & -19.86 & 5.73 & 1.78 \\
\hline & & 0.6 & 50 & 1.0 & 1 & 1.5 & 95 & 3.98 & -7.01 & 5.65 & 0.36 \\
\hline & & 0.0 & 0 & 1.0 & 1 & 1.0 & 90 & 3.75 & -12.38 & 4.39 & -22.02 \\
\hline & & & & & & & 85 & 3.41 & -20.33 & 3.12 & -44.58 \\
\hline & & & & & & & 100 & 4.13 & -3.50 & 6.16 & 9.41 \\
\hline MSF9 & 0.3 & 0.6 & 50 & 1.5 & 1 & 1.5 & 95 & 4.05 & -5.37 & 6.08 & 7.99 \\
\hline & & & & & & & 90 & 3.98 & -1.87 & 5.39 & -4.26 \\
\hline & & & & & & & 85 & 3.26 & -7.00 & 5.25 & -6.75 \\
\hline
\end{tabular}

Note: w/b: water to binder ratio; F/c: fine to coarse aggregate ratio; GSF: glued steel fibres; Acl: accelerator; PCE: polycarboxylic ether based superplasticizer; $+\mathrm{ve}$ sign indicates the increasing trend and -ve sign indicates the decreasing trend.

vibrator for 30 seconds and top surface leveled to smooth surface using trowel; after that the moulds were securely placed in room temperature for 24 hours. After 24 hours, the hardened concrete cubes were remolded and all the specimens were kept in the normal potable water curing tank for complete hydration of concrete and tested at different curing days.

\section{Experimental Test Results and Discussions}

3.1. Size Reduction. The effect of fibre addition in concrete is a major application used widely in industrial floor concreting and has been tested successfully in many applications. The important advantage of using steel fibres can be derived in reducing the concrete thickness. This is essentially achieved due to the increase in the composite elastic modulus and improved matrix strengthening due to high elastic modulus of steel fibres. In the present study, the experimental test results on the flexural stress capacity of different fly ash concrete specimens containing different volume fraction of steel fibres are summarized in Table 5. The study is intended mainly to check the accountability of the reduced depth of concrete with the addition of different percentage of glued steel fibers. Glued steel fibers used were of $35 \mathrm{~mm}$ length and 


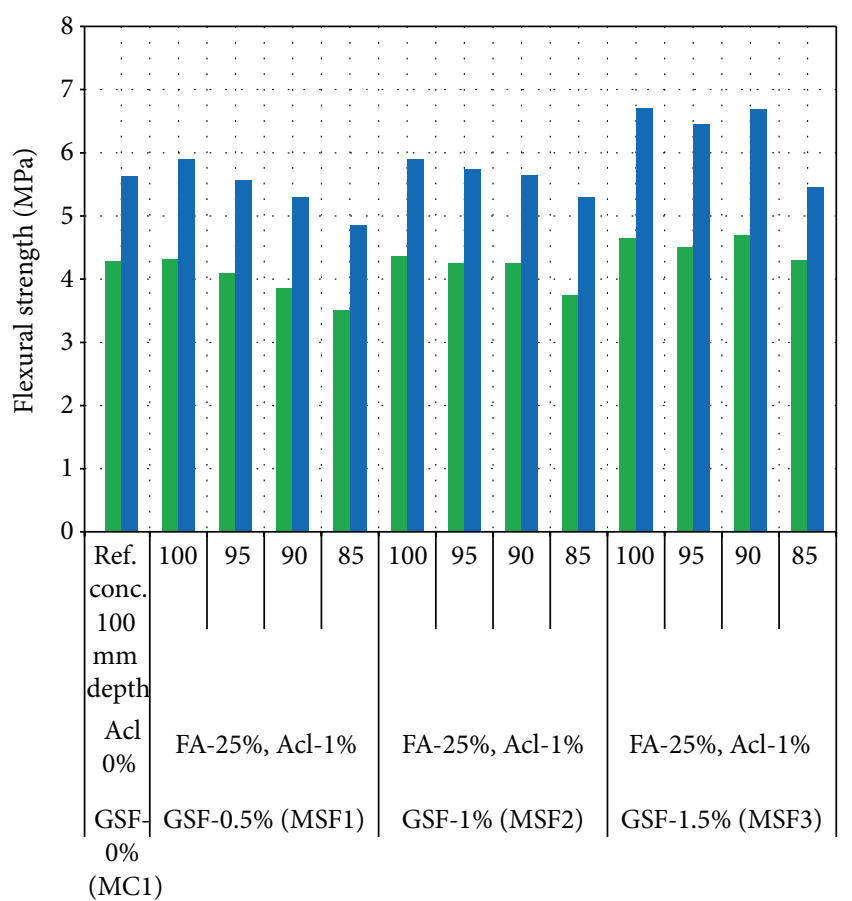

Different thickness of concrete specimens ( $\mathrm{mm})$

7 days

- 28 days

FIGURE 3: Flexural strength of concrete for various mixes of concrete with different percentage of steel fibres (size reduction).

$0.5 \mathrm{~mm}$ diameter $(l / d$ ratio 70$)$ at $0.5 \%, 1.0 \%$, and $1.5 \%$ by volume fraction $\left(V_{f}\right)$ of concrete, respectively.

The effect of steel fibre addition in fly ash based concrete $(\mathrm{F} / \mathrm{c}$ ratio 0.6$)$ showed better strength enhancement, when compared to normal size of concrete specimen (MC1) of $100 \mathrm{~mm}$ depth. The reduced size of concrete beam specimens of $90 \mathrm{~mm}$ thickness exhibited a higher flexural strength (MSF3) of around $4.70 \mathrm{MPa}$ and $6.69 \mathrm{MPa}$ at 7 and 28 days, respectively (as shown in Figure 3). In the case of 50\% fly ash concrete specimens showed a marginal increase in flexural stress up to $6.08 \mathrm{MPa}$ at 28 days (as shown in Figure 4). This essentially showed a better performance when compared to reference concrete of thickness $100 \mathrm{~mm}$ and the strength was increased up to $5.41 \%$ at 7 days and $14.56 \%$ at 28 days as shown in Figure 5. However, the effect of size reduction was realized at $5 \%$ reduction in thickness. Compared to reference concrete, the flexural strength showed a decrease of $5.37 \%$ at 7 days, whereas in the case of $50 \%$ fly ash substituted concrete mixes showed an increase of $7.99 \%$ at 28 days (as shown in Figure 6). It can be justified that a maximum size reduction was possible up to $5 \%$ and $10 \%$ of overall depth of concrete specimen in the case of low and high volume fly ash concretes. The effect of high early strength concrete specimens and the additional reinforcing mechanism can possibly result in the composite increase in the flexural properties. This provides a possible reduction in thickness compared to plain concrete without accelerated properties with the addition of either accelerating admixtures or steel fibres. It can be noted that

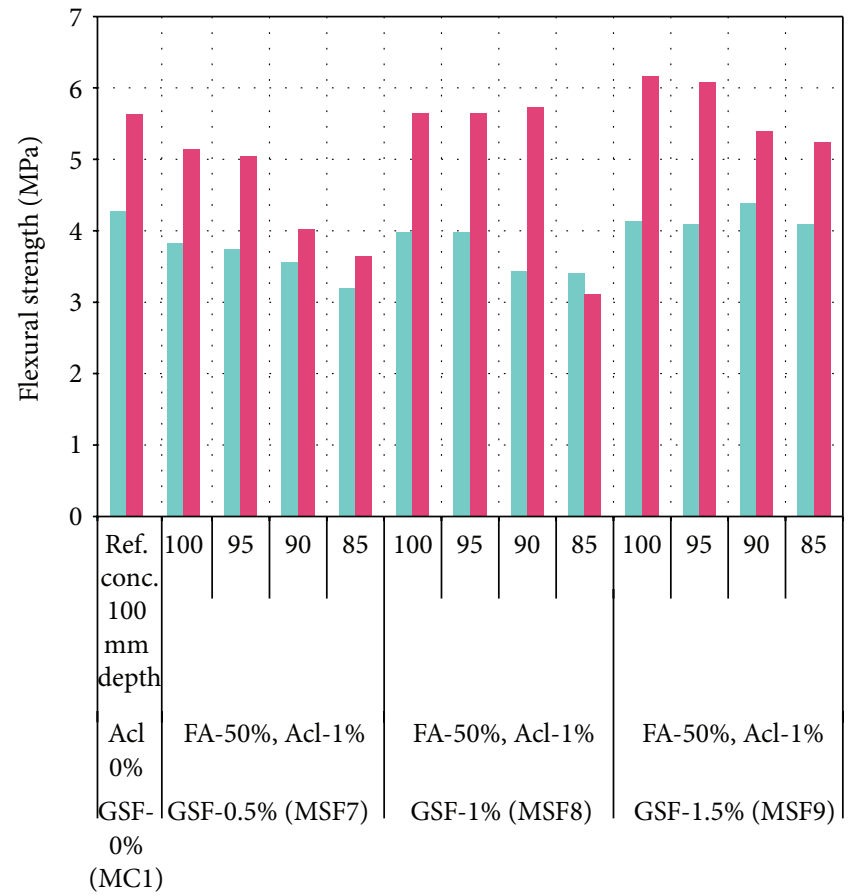

Different thickness of concrete specimens (mm)

I. 7 days

- 28 days

FIGURE 4: Flexural strength of concrete for various mixes of concrete with different percentage of steel fibres (size reduction).

the size reduction of concrete elements can be achieved up to $10 \%$ with $25 \%$ of low volume and $5 \%$ with $50 \%$ of high volume fly ash substituted high strength concrete mixes. A maximum increase up to $18.83 \%$ in flexural stress capacity was noted for low volume fly ash concrete mixes. The justifications for increased flexural performance even with the reduction in size and by compensating with steel fibre addition are discussed further. The increase in flexural stress capacity of steel fibre concrete is realized due to increase in steel fibre due to replacement of concrete area. This results in the increase in composite elastic modulus and reduction in brittle material. Also the ductility of concrete is essentially provided by high deformability of steel fibres. This also results in increased moment rotation capacity and hence leads to higher moment of resistance. However, beyond the optimized steel fibre addition and optimized thickness of concrete the reduction in the moment capacity is anticipated due to reduction in concrete area. The composite performance of steel fibres in concrete and the synergy between the reinforcing effects in matrix are provided when the area of both materials are adequate to develop the stress transfer mechanism. This is also justified from fundamental mechanics that during flexural loading the maximum strain in extreme fibre is reached first in concrete and stress redistribution occurs in the steel fibres. When the area of steel and steel fibres are present at optimum level, the development of ultimate strain occurs at the same time and this results in the increased stress 


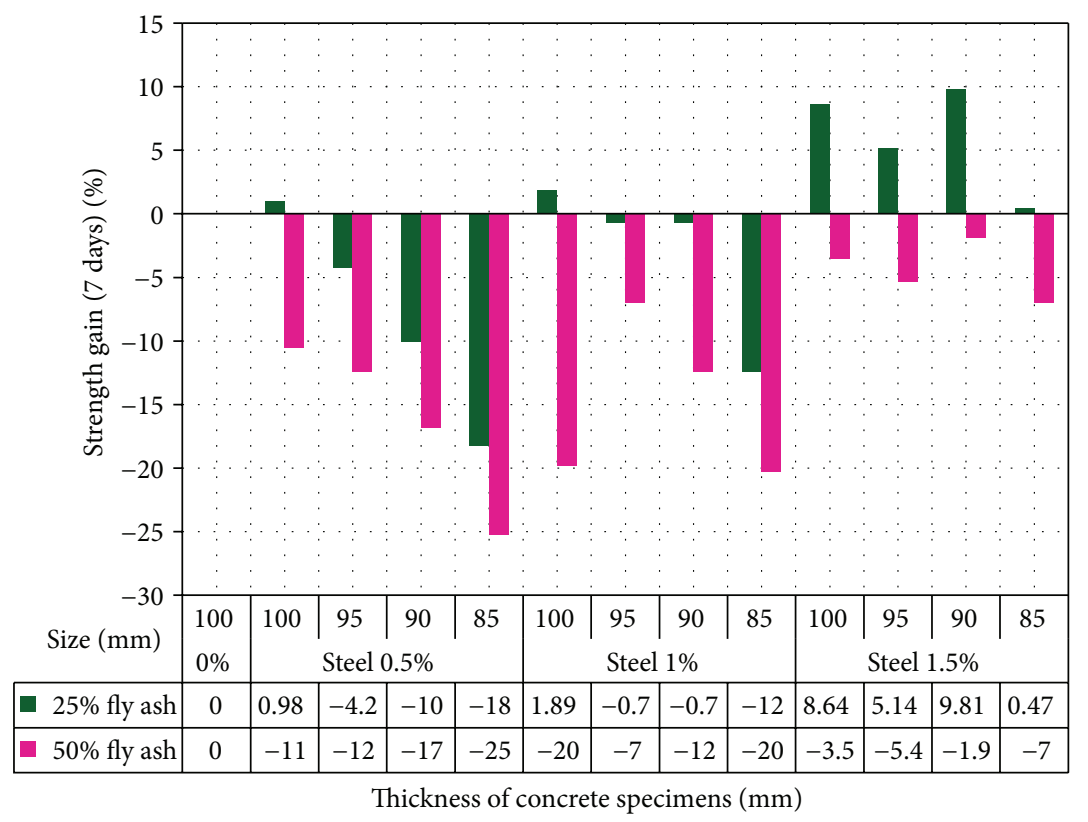

FIGURE 5: Percentage of strength gain for various mixture proportions of concrete at 7 days.

levels with failure occurring simultaneously in concrete and steel. This study comprehends the fundamental fact that the size of concrete element can be reduced up to $10 \%$ safely with the addition of steel fibre up to $1.5 \% V_{f}$ in the case of high early strength concrete. Moreover the development of increased flexural stress capacity of high early strength concrete is one important criterion for selecting the size reduction of concrete. However, a decreased strength was recorded in the case of $50 \%$ of fly ash addition in concrete for $\mathrm{F} / \mathrm{c}$ ratio $(0.6)$ with different percentage of steel fibres. The depth of concrete specimens $(85 \mathrm{~mm})$ exhibits a lower flexural strength of around $4.14 \mathrm{MPa}$ and $5.25 \mathrm{MPa}$ at 7 and 28 days, respectively, when compared to plain concrete up to $3.27 \%$ and $6.75 \%$ at 7 and 28 days, respectively.

3.2. Flexural Toughness. The flexural toughness values were calculated for the various mixture proportions of concrete and are provided in Table 6 . The load deformation characteristics for $25 \%$ and $50 \%$ fly ash substituted concrete mixes for various dosages of steel fibre addition are provided in Figures 7 and 8. The experimental trends showed that the increase in fibre dosage had shown a gradual improvement on the postpeak characteristics of fly ash concrete composites. The most accountable effect of steel fibres showed better bridging effects to resist the crack and increases the ductility properties of concrete specimens to exhibit a stable postpeak load deflection curve, when compared to plain concrete specimens. It can be noted that plain concrete had not shown significant postcracking behavior and the effect of steel fibre concrete mixes provided enough energy absorbing mechanism. Most importantly the composite flexural performance was dependent on the steel fibre content and the flexural strain hardening properties were greatly improved with higher steel fibre dosage. This is revealed in the case of steel fibre concrete mix (MSF3) exhibiting the highest absolute toughness value of $34.37 \mathrm{~N}-\mathrm{m}$ in the case of low volume fly ash concrete with maximum steel fibre content $\left(1.5 \% V_{f}\right)$. The same mix (MSF3) had also shown a maximum postcrack toughness of $27.97 \mathrm{~N}-\mathrm{m}$. In the case of residual toughness the maximum value was $24.27 \mathrm{~N}-\mathrm{m}$ for the same mix. In the case of $50 \%$ fly ash substituted concretes the maximum absolute toughness was $29.61 \mathrm{~N}-\mathrm{m}$, postcrack toughness $25.86 \mathrm{~N}-\mathrm{m}$, and residual toughness $17.87 \mathrm{~N}-\mathrm{m}$. The toughness results obtained for the various steel fibre substituted fly ash mixes exhibited a higher efficiency of matrix reinforcing efficiency and as a result the ductility of fibres provided adequate postelastic deformation properties. Also, the fly ash mixed cementitious system could possibly develop adequate bond with the steel fibre incorporated mixes due to which the residual toughness values were also found to be increased. It can be justified that the postcrack performance characteristics of high early strength concretes depend on the matrix reinforcing efficiency and result in higher energy mechanism. Also, the possible development of early strength gain properties and the synergistic interaction of steel fibres with the fly ash cement matrix can provide composite toughness properties. The load deformation characteristics for $25 \%$ and $50 \%$ fly ash substituted concrete mixes for various dosages of steel fibre addition are provided in Figure 9. It can be noted from the experimental trends that the increase in fibre dosage had shown a gradual improvement on the postpeak characteristics of fly ash concrete composites.

3.3. Toughness Index. The ratio of average load carrying capacity offered after cracking (due to the presence of steel fibre reinforcement) divided by the flexural tensile strength of the uncracked concrete specimen provides the $\mathrm{Re}_{3}$ index or also called toughness index. As expected, an increase in the 


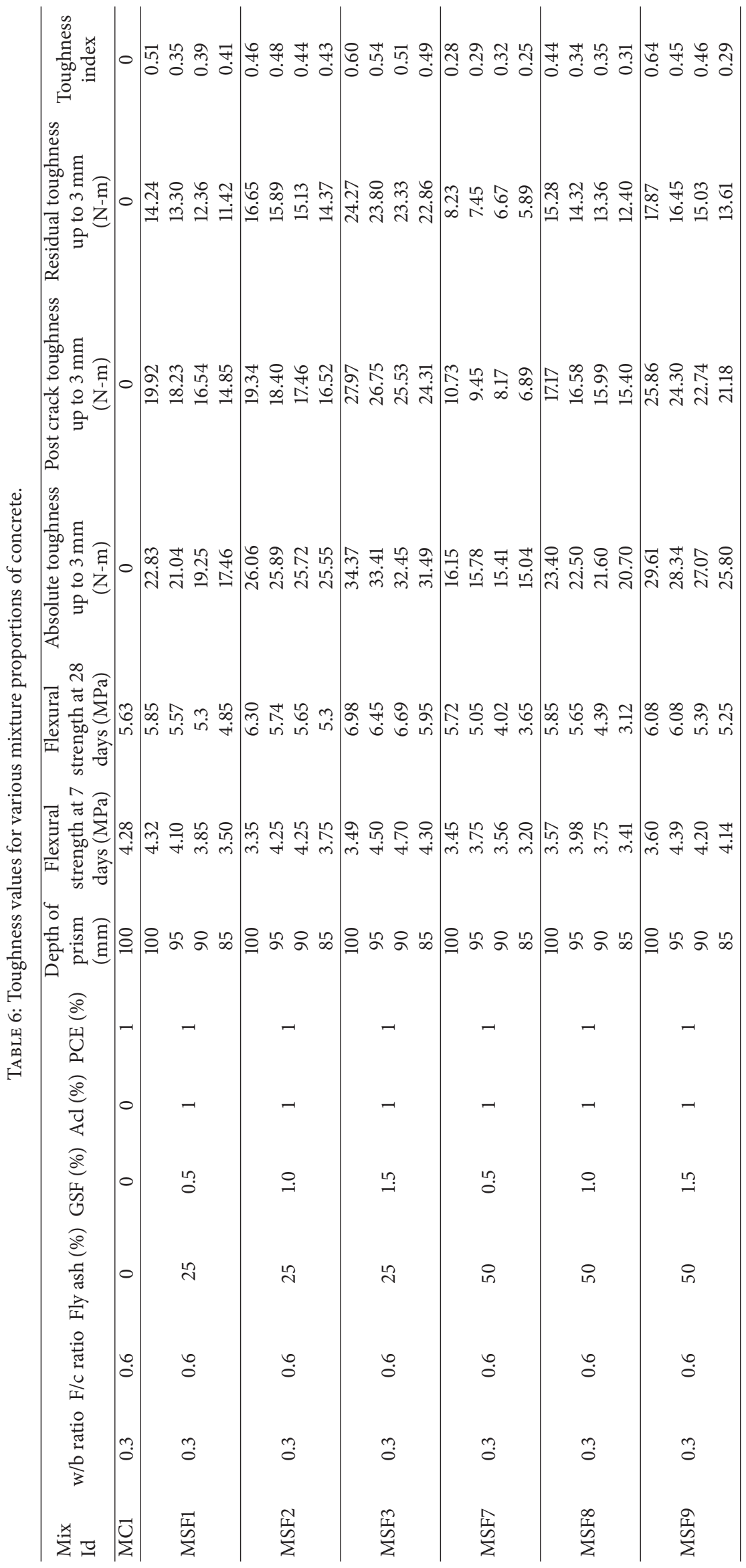




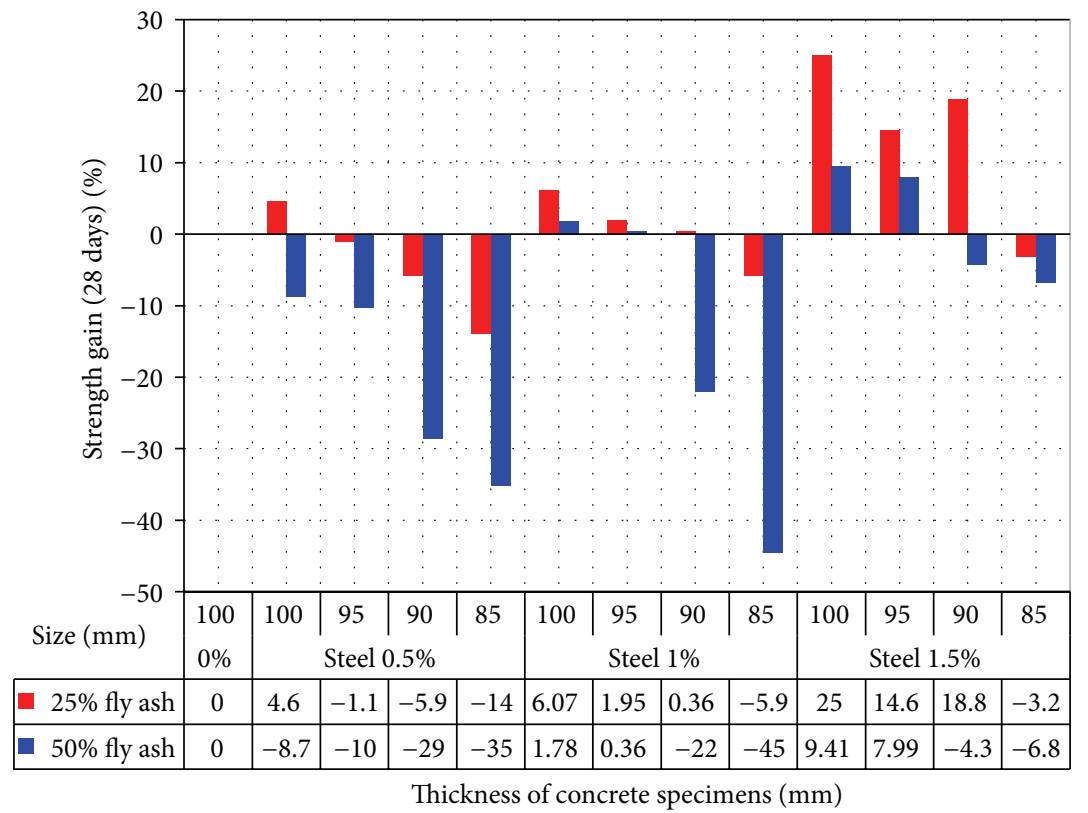

FIGURE 6: Percentage of strength gain for various mixture proportions of concrete at 28 days.

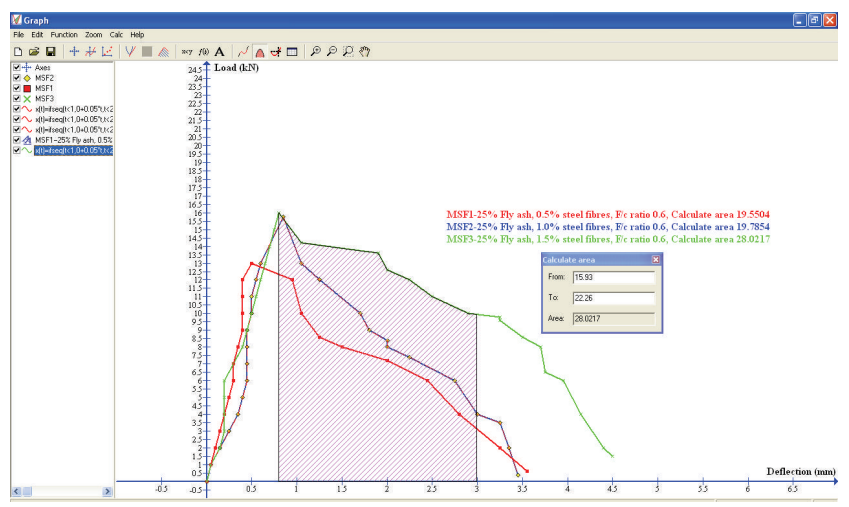

FIGURE 7: Flexural toughness graph containing $25 \%$ of fly ash with $0.5 \%, 1.0 \%$, and $1.5 \%$ of steel fibres.

percentage of steel fibres by volume fractions with $50 \%$ of fly ash based concrete ( $\mathrm{F} / \mathrm{c}$ ratio 0.6 ) showed better improvement on the $\mathrm{Re}_{3}$ index which was around 0.64 in 28 days, when compared to $25 \%$ of fly ash substituted concretes. Also, in the case of $50 \%$ fly ash substituted concretes a maximum toughness index value of 0.64 was noted with higher steel fibre content. This also denoted that the effect of fibres plays a major role in the strain softening zone due to which the contribution of steel fibres is predominant. However the matrix efficiency and further improvement on the prepeak strain hardening are due to matrix strengthening by steel fibres. The test results suggest that the distribution of steel fibres is maximum at higher reinforcement index (volume of fibres to volume of concrete). The test results showed the effects of fly ash concrete mixes at $0.6 \mathrm{~F} / \mathrm{c}$ ratio of different volume fraction of steel fibres. It can be concluded from the above evaluation that the effects of steel fibres were much realized in high early strength concrete mixes in flexural strength and toughness properties.

3.4. Fibre Bridging Effects in Concrete. The effective fibre bridging by steel fibres (shown in Figure 10) occurred even after the failure had resulted in the concrete beam and showed a significant enhancement on the postpeak characteristics. It is understood from the above test results that the prepeak strain hardening characteristics are dependent on the matrix densification and hardening properties of cementitious systems. However, the postpeak strain softening characteristics of concrete are dependent on the crack bridging properties offered by the steel fibres. In general, the steel fibre addition showed a synergistic effect with the pozzolanic reaction of fly ash with cement and showed improved strength compared to controlled concrete mixtures.

3.5. Fibre Alignment. The orientations of steel fibres in the various concrete mixtures are provided in Figures 11 and 12, which represents the microscopic image of sliced concrete section. It can be seen from the micrographs that the steel fibres were found to align along the direction of beam axis which was found to be an important property for the enhancement in the flexural strength in the case of fibre reinforced concrete specimens. It can be seen that the steel fibres oriented along the beam axis contribute towards the flexural strength capacity of the various fibre concrete mixes. However, the orientation of fibres along the transverse direction can be easily seen in the sliced concrete section in which case the fibres were oriented along the longer direction. Also, the fibres which are oriented along the beam axis can be seen as circular shape and this evidently shows the contribution of steel fibres in matrix. In the case of steel fibre reinforced concrete specimens the distribution of steel 


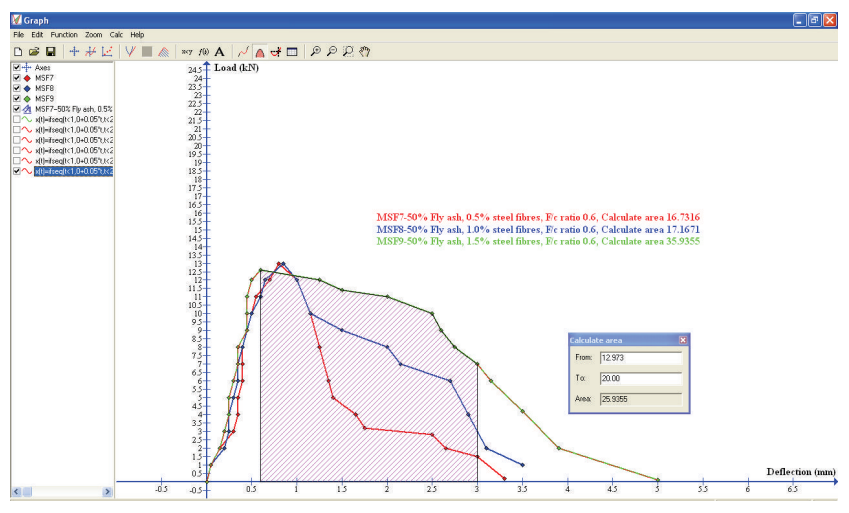

FIGURE 8: Flexural toughness graph containing $50 \%$ of fly ash with $0.5 \%, 1.0 \%$, and $1.5 \%$ of steel fibres.

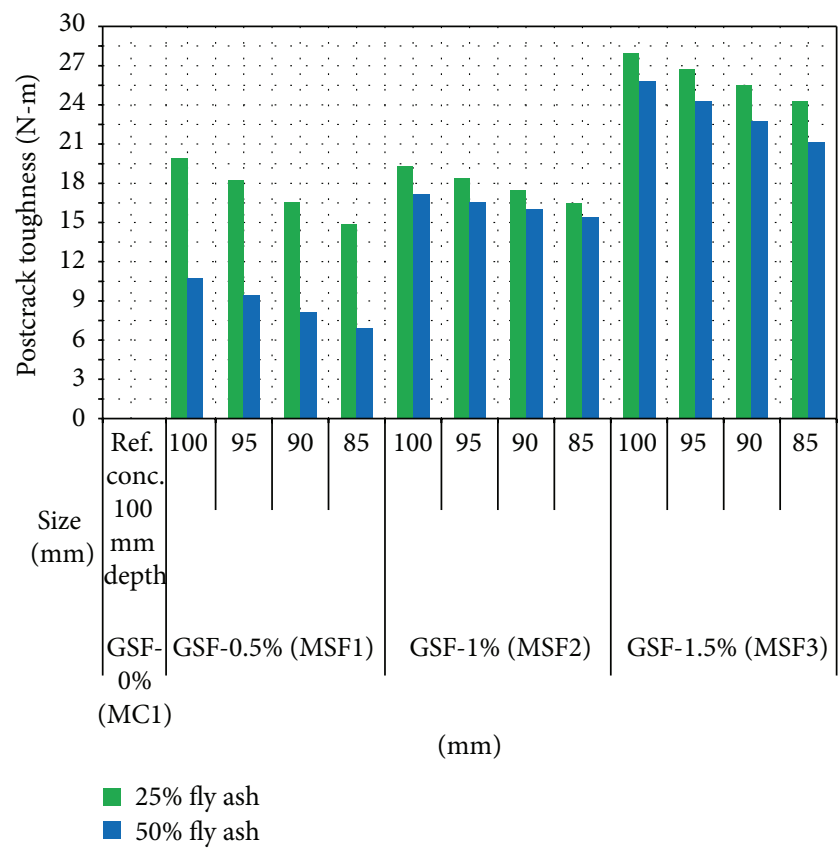

FIGURE 9: Postcrack toughness for various mix proportions of concrete.

fibres along the given cross section can be easily counted in terms of number of fibres seen visually in the case of different concrete mixes. The number of fibres in all the concrete mixes was accounting for the flexural stress carrying capacity. The orientation of steel fibres is found to be directly influencing the stress redistribution in concrete system in which case the plain concrete tends to fail immediately after first crack whereas in the case of steel fibre reinforced concrete specimens, it can be seen that the flexural stress carrying capacity is enhanced with the closer facing of steel fibres. Most notably the consecutive stress transfer mechanism is much effective in all the fibre reinforced concrete specimens as well as the reinforcement index. Reinforcing efficiency depends on the distribution of steel fibres for a given area and is represented clearly in this sliced concrete section. It can be seen that in the case of higher volume fraction of steel

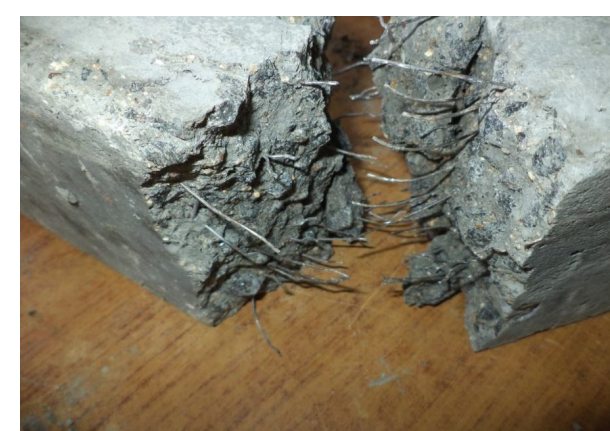

FIGURE 10: Snapshot of fibre bridging effects.

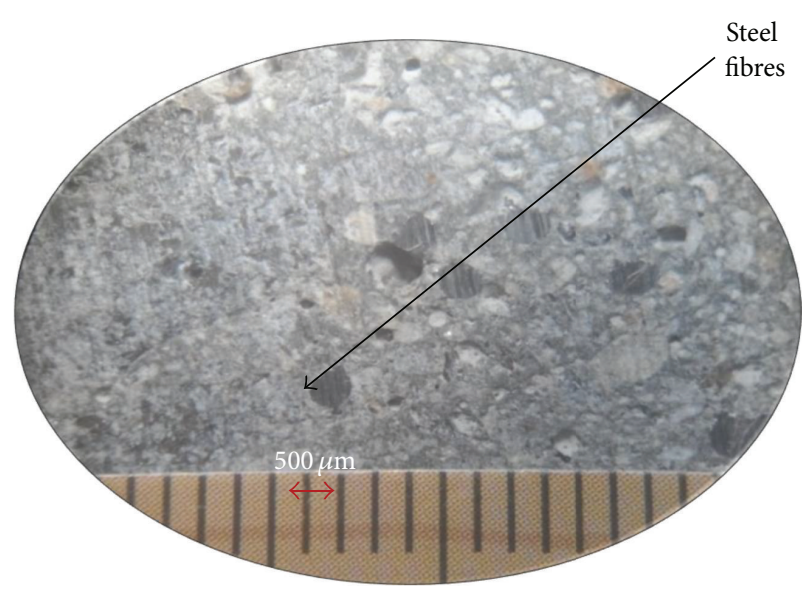

FIGURE 11: Microscopic view of $25 \%$ of fly ash with $1.5 \%$ of steel fibre concrete.

fibres, the homogeneous distribution of steel fibres is clearly evident and is represented by the closer spacing of fibres, whereas, in the case of low volume fraction the orientation and distribution of steel fibres were random with large inter fibre spacing. Also, it is observed that the orientations of steel fibres were affected during the vibration of the concrete and have the tendency of the longer fibres to get aligned along the direction of the beam axis. High modulus steel fibres influence matrix strengthening in the case of high volume fly ash (50\%) concrete systems. This also apparently enhanced the flexural strength on par that of $25 \%$ fly ash substituted concretes mixes. Even though the matrix is highly brittle but the addition of fibres had shown a considerable increase in the flexural stress carrying capacity. The experimental test results indicated that the addition of steel fibres has proved to be essential to the matrix strengthening as well as in the case of overall composite performance of fly ash substituted steel fibres reinforced concrete mixes.

\section{Conclusions}

Based on the experimental investigation the following significant conclusions are drawn within the limitations of the study. 


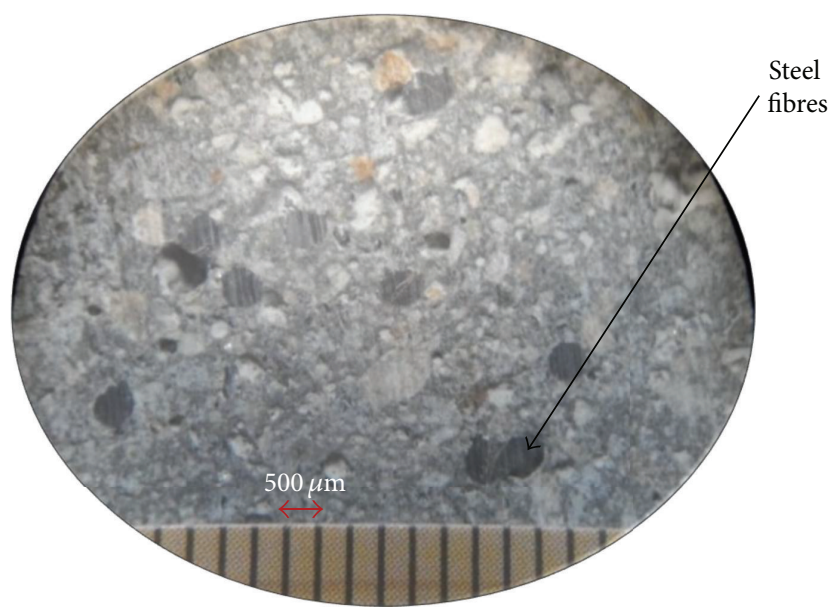

Figure 12: Microscopic view of $50 \%$ of fly ash with $1.5 \%$ of steel fibre concrete.

(i) The size reduction of structural element can be an important aspect for improving the concrete performance in terms of structural efficiency and economy.

(ii) From the studies it was noticed that the addition of steel fibres at higher volume fraction $\left(1.5 \% V_{f}\right)$ showed good reduction in thickness of beam element for about $10 \%$, which resulted in higher bending resistance, when compared to plain concrete.

(iii) Also, compared to plain concrete the addition of steel fibres in concrete provided higher reinforcing index for the decreased volume reduction of concrete.

(iv) It can be concluded that the reinforcing index of steel fibre concrete can be much improved in terms of strength and stiffness of the structural element.

(v) It is clear from the studies that fibre reinforced cement composites provide better performance characteristics than conventional concrete and have opened up a variety of new and exciting construction materials.

(vi) Most importantly the composite flexural properties were dependent on the steel fibre content and the flexural strain hardening properties were greatly improved with higher steel fibre dosage. This is revealed in the case of steel fibre concrete mix (MSF3) exhibiting the highest absolute toughness value of $34.37 \mathrm{~N}-\mathrm{m}$ in the case of low volume fly ash concrete with maximum steel fibre content $\left(1.5 \% V_{f}\right)$. The same mix (MSF3) had also shown a maximum postcrack toughness of $27.97 \mathrm{~N}$-m. In the case of residual toughness the maximum value was $24.27 \mathrm{~N}$ $\mathrm{m}$ for the same mix. In the case of $50 \%$ fly ash substituted concretes the maximum absolute toughness was $29.61 \mathrm{~N}-\mathrm{m}$, postcrack toughness $25.86 \mathrm{~N}-\mathrm{m}$, and residual toughness $17.87 \mathrm{~N}-\mathrm{m}$.

(vii) Residual load capacity of fibre concretes was found to exhibit the flexural strength capacity of all fibre concrete mixes after the initiation of first crack and subsequent reloading till failure. (viii) It was observed from the test results that the higher toughness index (0.60) was noticed in the case of low volume fly ash concrete with $1.5 \% V_{f}$ of steel fibres.

\section{Conflict of Interests}

The authors declare that there is no conflict of interests regarding the publication of this paper.

\section{References}

[1] V. S. Gopalaratnam and R. Gettu, "On the characterization of flexural toughness in fiber reinforced concretes," Cement and Concrete Composites, vol. 17, no. 3, pp. 239-254, 1995.

[2] ACI Committee 207, "Effect of restraint, volume change, and reinforcement on cracking of mass concrete," ACI Committee 207 Report ACI 207.2R-95, American Concrete Institute, Farmington Hills, Mich, USA, 1995.

[3] R. N. Swamy and H. stavrides, "Some properties of high workability steel fibre concrete," in Fibre-Reinforced Cement and Concrete, RILEM Symposium, pp. 197-208, The Construction Press, 1975.

[4] M. C. Nataraja, T. S. Nagaraj, and S. B. Basavaraja, "Reproportioning of steel fibre reinforced concrete mixes and their impact resistance," Cement and Concrete Research, vol. 35, no. 12, pp. 2350-2359, 2005.

[5] C. Cucchiara, L. la Mendola, and M. Papia, "Effectiveness of stirrups and steel fibres as shear reinforcement," Cement and Concrete Composites, vol. 26, no. 7, pp. 777-786, 2004.

[6] Ö. Eren and T. Çelik, "Effect of silica fume and steel fibers on some properties of high-strength concrete," Construction and Building Materials, vol. 11, no. 7-8, pp. 373-382, 1997.

[7] F. Koksal, A. Ilki, F. Bayramov, and M. A. Tasdemir, "Mechanical behavior and optimum design of SFRC plates," in Proceedings of the 16th European Conference of Fracture, pp. 3-7, 2006.

[8] Y. Şahin and F. Köksal, "The influences of matrix and steel fibre tensile strengths on the fracture energy of high-strength concrete," Construction and Building Materials, vol. 25, no. 4, pp. 1801-1806, 2011.

[9] Ş. Yazici and H. Ş. Arel, "The effect of steel fiber on the bond between concrete and deformed steel bar in SFRCs," Construction and Building Materials, vol. 40, pp. 299-305, 2013. 
[10] H. A. Toutanji, "Properties of polypropylene fiber reinforced silica fume expansive-cement concrete," Construction and Building Materials, vol. 13, no. 4, pp. 171-177, 1999.

[11] C. D. Atiş and O. Karahan, "Properties of steel fiber reinforced fly ash concrete," Construction and Building Materials, vol. 23, no. 1, pp. 392-399, 2009.

[12] C. Berryman, J. Zhu, W. Jensen, and M. Tadros, "Highpercentage replacement of cement with fly ash for reinforced concrete pipe," Cement and Concrete Research, vol. 35, no. 6, pp. 1088-1091, 2005.

[13] C.-H. Huang, S.-K. Lin, C.-S. Chang, and H.-J. Chen, "Mix proportions and mechanical properties of concrete containing very high-volume of Class F fly ash," Construction and Building Materials, vol. 46, pp. 71-78, 2013.

[14] BIS (Bureau of Indian Standards), IS 12269: Specification for 53 Grade Ordinary Portland Cement, Bureau of Indian Standards, New Delhi, India, 1987. 

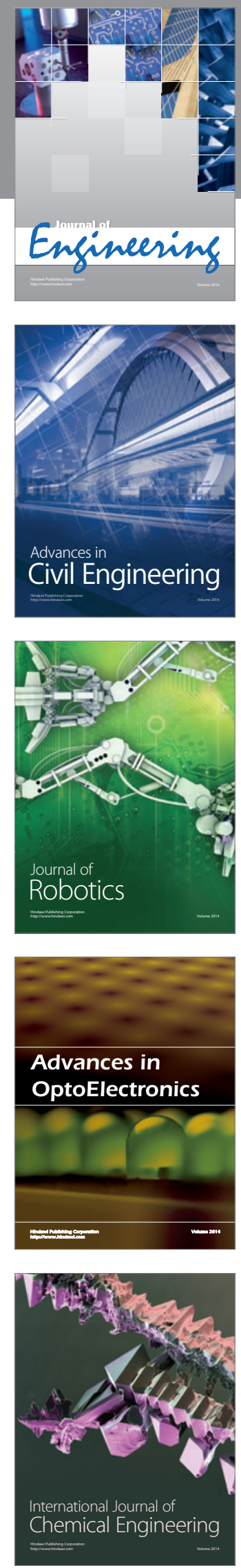

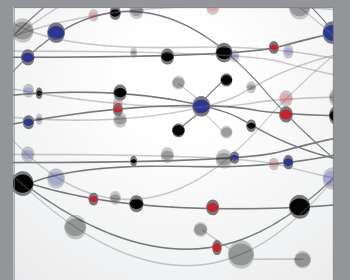

The Scientific World Journal
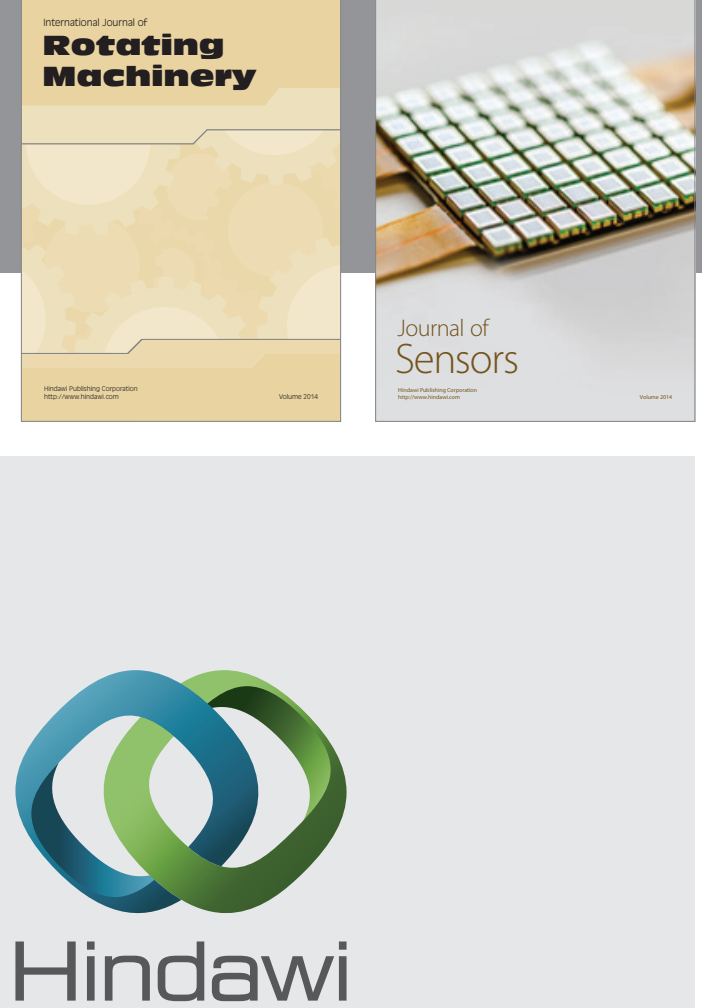

Submit your manuscripts at http://www.hindawi.com
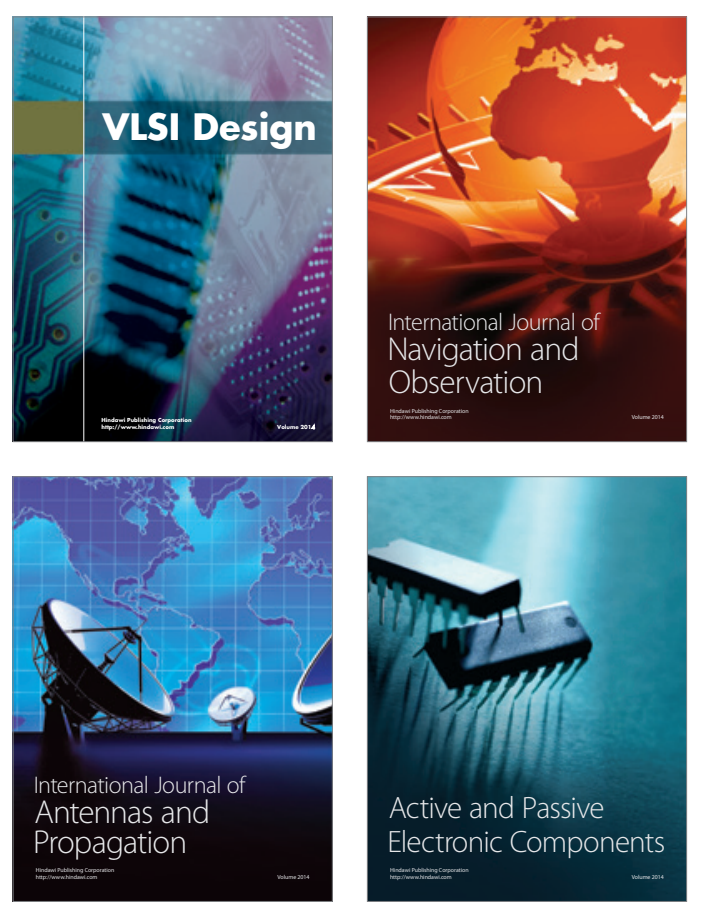
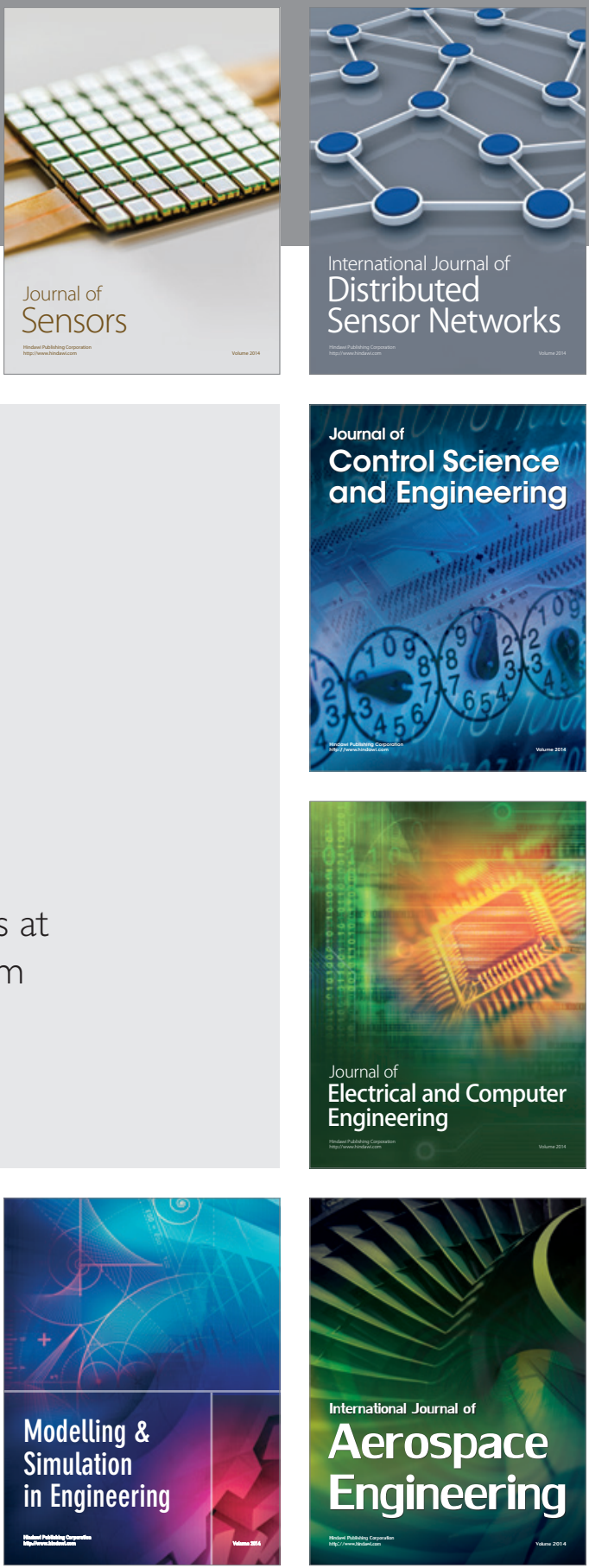

Journal of

Control Science

and Engineering
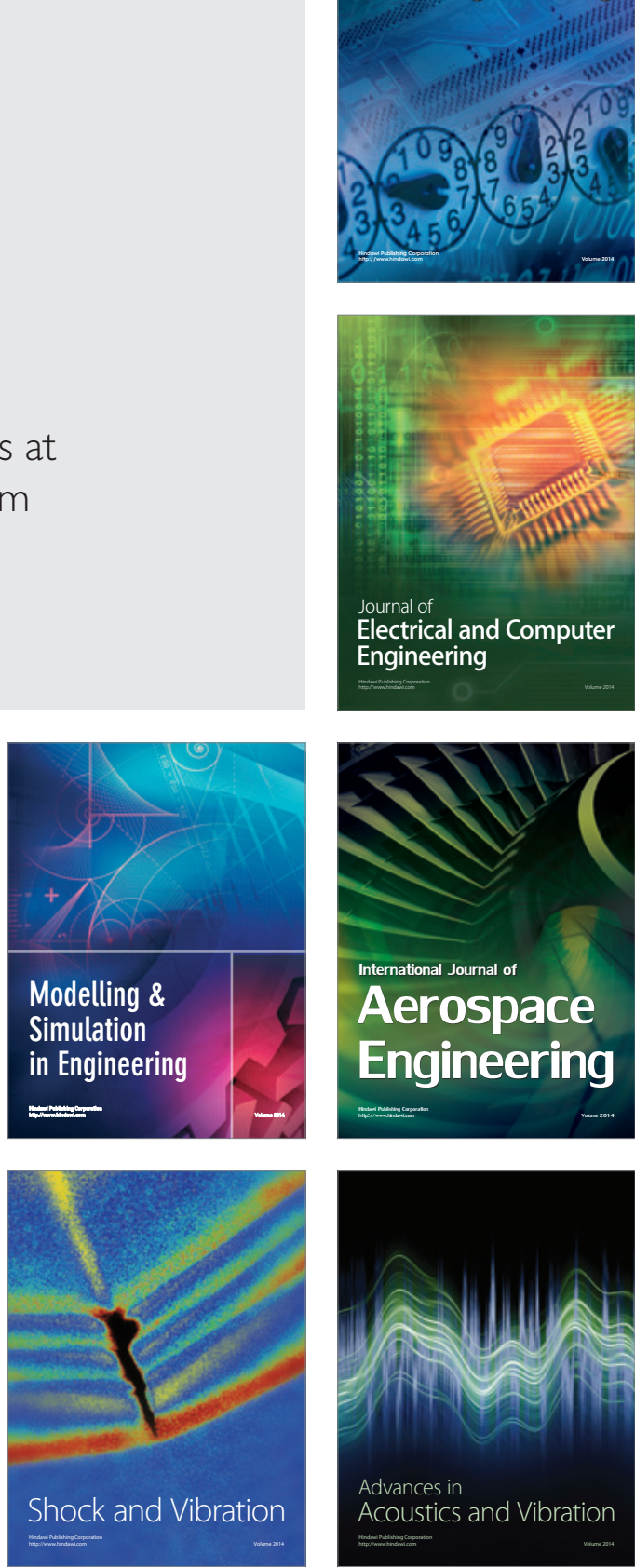